Rev Biomed 2001; 12:272-280.

\title{
Interleucinas e inmunidad innata.
}

Revisión

Miguel A. Hernández-Urzúa, Anabell Alvarado-Navarro.

Centro de Investigación en Inmunología y Dermatología (CIINDE), Universidad de Guadalajara. Guadalajara, Jalisco, México.

\section{RESUMEN.}

La comunicación entre células inmunes e inflamatorias es mediada en gran parte por proteínas llamadas interleucinas, que promueven crecimiento, diferenciación y activación celular. Estas moléculas efectoras son producidas transitoriamente y controlan localmente la amplitud y duración de la respuesta. En ésta revisión son descritas tanto las interacciones entre citocinas y células, así como las principales características biológicas de las interleucinas involucradas en la respuesta inmune innata: IL-1, IL-6, quimiocinas, IL-10, IL-12, IL-15, IL-18, TNF-a e IFN-a, -b.

(Rev Biomed 2001; 12:272-280)

Palabras clave: Interleucinas, Citocinas, Inmunidad Innata, Infección.

\section{SUMMARY. \\ Interleukins and innate immunity.}

The communication between immune and inflammatory cells is mediated in large part by proteins, termed interleukins, which are able to promote cell growth, differentiation, and functional activation. These effector molecules are produced transiently and controll locally the amplitude and duration of the response. In this review, cytokinecell interactions as major biological characteristics of interleukins involved in innate immune response IL-1, IL-6, chemokines, IL-10, IL-12, IL-15, IL18, TNF-a and IFN-a, -b are outlined. (Rev Biomed 2001; 12:272-280)

Key words: Interleukins, Cytokines, Innate immunity, Infection.

\section{INTRODUCCIÓN.}

La principal función fisiológica del sistema inmune es proteger al hospedero contra microbios patógenos, tradicionalmente ha sido dividido en

Solicitud de sobretiros: M. en C. Miguel A. Hernández-Urzúa. Centro de Investigación en Inmunología y Dermatología (CIINDE), Universidad de Guadalajara.Federalismo Norte 3102, Instituto Dermatológico, C.P. 44 220, Guadalajara, Jalisco. Teléfono y FAX: (3) 6722848

E-mail: angelhdez@terra.com.mx

Recibido el 13/Diciembre/1999. Aceptado para publicación 29/Junio/2001 
MA Hernández-Urzúa, A Alvarado-Navarro.

inmunidad innata e inmunidad adquirida (1). Las principales diferencias entre ambas respuestas son los mecanismos y los tipos de receptores usados para el reconocimiento antigénico. En la inmunidad específica, los receptores reconocen a los microorganismos infecciosos e identifican antígenos propios y del medio. Esto es dañino para el hospedero, ya que la activación del sistema inmune por tales antígenos puede conducir a enfermedades autoinmunes y alergias. En cambio, en la inmunidad natural, los receptores reconocen estructuras altamente conservadas presentes en un gran grupo de microorganismos (2). Estas estructuras son designadas patrones moleculares asociados a patógenos (PAMPs) y los receptores involucrados en identificarlas son llamados receptores para reconocimiento del patrón (3).

La delimitación entre inmunidad innata e inmunidad adquirida no es posible. Después de la identificación del microorganismo, las señales producidas por la inmunidad inespecífica, controlan aspectos de la inmunidad especifica. Igualmente, la respuesta adaptativa puede dirigir a la respuesta innata contra agentes infecciosos, como en el caso de la citotoxicidad celular mediada por anticuerpos. Ambas respuestas inmunes son reguladas en gran parte por un grupo de proteínas llamadas interleucinas o citocinas (4). Nuestra discusión se enfocará en las citocinas que participan en la inmunidad innata.

\section{LA MAQUINARIA.}

En la inmunidad innata intervienen las barreras físicas y químicas, tales como: el epitelio y las sustancias antimicrobianos producidas en las superficies epiteliales (criptidinas en el intestino delgado). Las proteínas plasmáticas, las cuales incluyen miembros del sistema de complemento, proteínas de fase aguda y otros mediadores de inflamación. Las células NK, linfocitos Tgd y células B-1, neutrófilos, macrófagos y leucocitos granulares (5). Los fagocitos realizan una labor de gran importancia, ya que son los principales productores de las citocinas IL-1, IL-6, IL-8, IL-
12 y TNF-a y además liberan otras moléculas como: la enzima activadora de plasminógeno y fosfolipasa, radicales de oxígeno, peróxido, factor activador de plaquetas, óxido nítrico y mediadores lipídicos de inflamación, tales como prostaglandinas y leucotrienos (6).

\section{LAS INTERLEUCINAS.}

Son proteínas solubles de bajo peso molecular mediadoras de crecimiento celular, inflamación, inmunidad, diferenciación y reparación, entre otras actividades. Además de las células del sistema inmune, las citocinas son producidas por diferentes tipos celulares durante la activación de la inmunidad innata y adquirida. Son el principal medio de comunicación intracelular ante una invasión microbiana. Las citocinas sirven para iniciar la respuesta infamatoria, y para definir la magnitud y naturaleza de la respuesta inmune específica (7). En el cuadro 1, se enlistan las principales características de las citocinas involucradas en la respuesta inmune inespecífica (8-28).

\section{INTERACCIONES ENTRE INTERLEUCINAS Y CÉLULAS EN LA RESPUESTA INMUNE INNATA.}

Los agentes patógenos generalmente deben atravesar la barrera epitelial para poder multiplicarse dentro de los tejidos y así producir enfermedad. Las defensinas y los otros péptidos son unas de las primeras líneas de defensa contra microorganismos. El mecanismo de toxicidad para estas moléculas, consiste de una rápida permeabilización de la membrana celular del invasor (29). Otras proteínas importantes, son los anticuerpos naturales, los cuales evitan la propagación de infecciones por vía sanguínea (30). Los factores del complemento desempeñan un papel clave. Las bacterias gram negativas contienen peptidoglicanos en su pared celular que activan la vía alterna del complemento (figura 1). El complejo de ataque de membrana, lisa especialmente a la Neisseria. Algunos receptores para reconocimiento del patrón son secretados por el hígado y funcionan

\section{Revista Biomédica}


Interleucinas e inmunidad innata.

\section{Cuadro 1}

Principales características de la inmunidad innata.

\begin{tabular}{|c|c|c|c|c|}
\hline Interleucina & Nombre Original & Fuentes & Estímulos & Definición \\
\hline $\begin{array}{l}\text { IL-1 } \\
\sim 17,5 \mathrm{kDa}\end{array}$ & $\begin{array}{l}\text { Factor activador de } \\
\text { Linfocitos (LAF) }\end{array}$ & $\begin{array}{l}\text { Fagocitos mononucleares activados } \\
\text { Células epiteliales y endoteliales }\end{array}$ & $\begin{array}{l}\text { Bacterias y sus productos } \\
\text { Citocinas IL-1 y TNF } \\
\text { Contacto con célula T CD4 }\end{array}$ & $\begin{array}{l}\text { Mediador de la } \\
\text { inflamatoria en } \\
\text { la inmunidad innata }\end{array}$ \\
\hline PM $26 \mathrm{kDa}$ & $\begin{array}{l}\text { Factor con actividad } \\
\text { antiviral secretado por } \\
\text { fibroblastos } \\
\text { "Interferon beta 2" }\end{array}$ & $\begin{array}{l}\text { Fagocitos mononucleares activados } \\
\text { Células de endotelio vascular y } \\
\text { fibroblastos, otras células en } \\
\text { respuesta a IL-1 y TNF } \\
\text { Algunas células T activadas }\end{array}$ & $\begin{array}{l}\text { Virus, vacterias y sus } \\
\text { productos IL-1, } \\
\text { TNF, IFN y PDGF }\end{array}$ & $\begin{array}{l}\text { Mediador de la } \\
\text { respuesta de } \\
\text { fase aguda }\end{array}$ \\
\hline $\begin{array}{l}\text { Quimiocinas } \\
15 \text { proteínas } \\
\text { de } 8 \text { a } 10 \mathrm{kDa}\end{array}$ & $\begin{array}{l}\text { Factor quimiotáctico } \\
\text { de neutrófilos derivado } \\
\text { de monocitos } \\
\text { (MDNCF) (ahora IL-8) }\end{array}$ & $\begin{array}{l}\text { Subfamilia C-C por: Linfocitos T } \\
\text { activados, Subfamilia C-X-C por: } \\
\text { Fagocitos mononucleares activados } \\
\text { Células tisulares (endotelio, fibro- } \\
\text { blastos) Megacariocitos }\end{array}$ & $\begin{array}{l}\text { Agentes infecciosos } \\
\text { y endotoxinas } \\
\text { Lectinas, IL-1 y TFN-a }\end{array}$ & Mediadoras de \\
\hline $\begin{array}{l}\text { IL-12 } \\
\text { PM } 75 \mathrm{kDa}\end{array}$ & $\begin{array}{l}\text { Factor estimulador } \\
\text { de células NK (NKSF) }\end{array}$ & $\begin{array}{l}\text { Células dentríticas } \\
\text { Macrófagos, Neutrófilos }\end{array}$ & $\begin{array}{l}\text { Bacterias y sus productos } \\
\text { Microorganismos } \\
\text { intracelulares }\end{array}$ & $\begin{array}{l}\text { Puente entre } \\
\text { inmunidad } \\
\text { y adaptativa }\end{array}$ \\
\hline $\begin{array}{l}\text { INF-a } \\
\sim 18 \mathrm{kDa} \\
\text { IFN-b } \\
20 \text { a } 23 \mathrm{kDa}\end{array}$ & $\begin{array}{l}\text { Factor secretado por } \\
\text { células infectadas con } \\
\text { virus, capaz de inter- } \\
\text { ferir con la infección } \\
\text { viral en otras células }\end{array}$ & $\begin{array}{l}\text { Fagocitos mononucleares } \\
\text { Interferon-b } \\
\text { Fibroblastos y otras células }\end{array}$ & $\begin{array}{l}\text { Infección viral } \\
\text { Presentación de MHC- } \\
\text { antígeno a TCR incremen- } \\
\text { tada por IL-2 e IL } 12 \\
\text { PHA o Concanavalina A }\end{array}$ & $\begin{array}{l}\text { Interfieren con } \\
\text { la replicación } \\
\text { viral }\end{array}$ \\
\hline $\begin{array}{l}\text { TNF-a } \\
\text { PM } 17 \text { kDa }\end{array}$ & $\begin{array}{l}\text { "Factor tóxico" } \\
\text { presente en el } \\
\text { sobrenadante de } \\
\text { cultivos de } \\
\text { linfocitos activados }\end{array}$ & $\begin{array}{l}\text { Fagocitos mononucleares activados } \\
\text { Células T estimuladas con antígeno } \\
\text { Células NK y mastocitos activados }\end{array}$ & $\begin{array}{l}\text { PMA, Células tumorales } \\
\text { Mycoplasma y LPS } \\
\text { IL-1, IL-3, TNF, GM-CSF } \\
\text { e IFN-g, entre otros }\end{array}$ & $\begin{array}{l}\text { Mediador de la } \\
\text { respuesta a } \\
\text { bacterias } \\
\text { Gram (-) }\end{array}$ \\
\hline $\begin{array}{l}\text { IL-15 } \\
14 \text { a } 15 \mathrm{kDa}\end{array}$ & $\begin{array}{l}\text { Linfoquina inductora } \\
\text { de proliferación } \\
\text { y activación de } \\
\text { células NK }\end{array}$ & $\begin{array}{l}\text { Monocitos activados } \\
\text { Células epiteliales y Fibroblastos }\end{array}$ & $\begin{array}{l}\text { Estímulos medioambientales } \\
\text { y agentes infecciosos }\end{array}$ & $\begin{array}{l}\text { s Mediadora } \\
\text { del crecimiento } \\
\text { de células T }\end{array}$ \\
\hline $\begin{array}{l}\text { IL-10 } \\
\text { PM } 18 \mathrm{kDa}\end{array}$ & $\begin{array}{l}\text { Factor inhibitorio } \\
\text { de la síntesis } \\
\text { de citocinas }\end{array}$ & $\begin{array}{l}\text { Macrófagos activados, } \\
\text { linfocitos T y B, y keratinocitos }\end{array}$ & $\begin{array}{l}\text { Interleucinas tipo } \\
\text { Th1 }\end{array}$ & $\begin{array}{l}\text { Función compleja } \\
\text { en la regulación } \\
\text { de la respuesta } \\
\text { inmune }\end{array}$ \\
\hline $\begin{array}{l}\text { IL-18 } \\
\text { ND }\end{array}$ & $\begin{array}{l}\text { Factor inductor de } \\
\text { IFN-g(IGIF) }\end{array}$ & $\begin{array}{l}\text { Macrófagos activados, } \\
\text { incluyendo células de Kupffer }\end{array}$ & Microorganismos & $\begin{array}{l}\text { Citocina } \\
\text { proinflamatoria }\end{array}$ \\
\hline
\end{tabular}


MA Hernández-Urzúa, A Alvarado-Navarro.

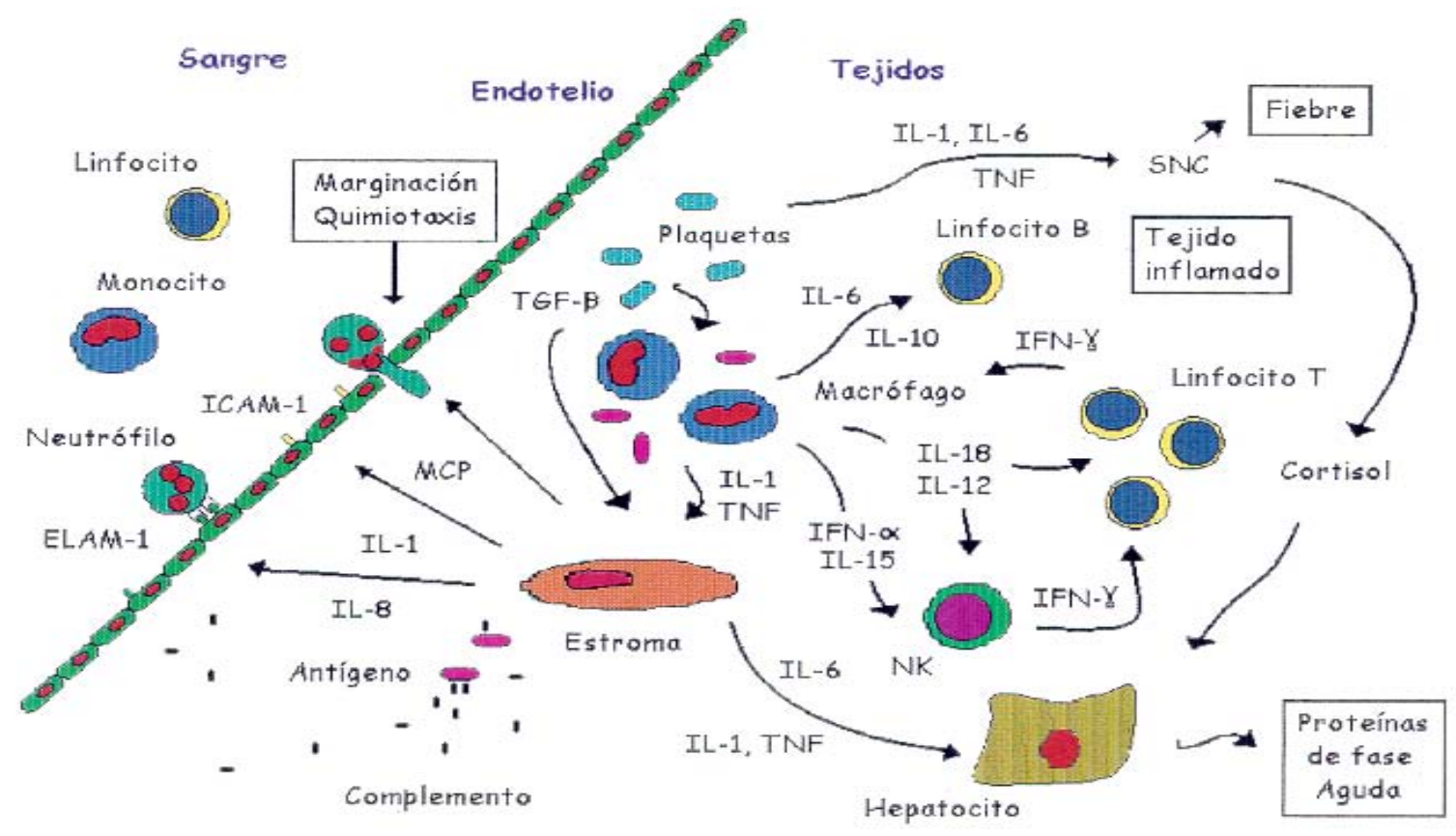

Figura 1.- Interacción entre interleucinas y células en la respuesta inmune innata. Las plaquetas y fagocitos mononucleares liberan citocinas, tales como IL-1, TNF y TGF-b durante la etapa temprana de la infección, en los sitios del reconocimiento antigénico. Estas interleucinas inducen la secreción de citocinas quimiotácticas IL-8 y MCP por las células estromales y la expresión de moléculas de adhesión ELAM-I e ICAM-I en las células endoteliales, para iniciar la acumulación de neutrófilos, macrófagos y células NK, que producen las interleucinas IFN-g, IL-12, IL-10, IL-15 e IL18, para activar Linfocitos T y B (células de la respuesta inmune específica) y así eliminar el antígeno del tejido blanco. Por otro lado, la respuesta hepática es activada por IL-1, IL-6 y TNF provocando el incremento sérico de las proteínas de fase aguda. La respuesta de los hepatocitos es modulada por el cortisol, el cual es producido en el SNC tras el estímulo de éstas mismas interleucinas, que a su vez regulan la reacción febril. Además, la vía alterna del complemento también participa en la fase efectora, ya sea a través de la formación del complejo de ataque de membrana o por la atracción de células inflamatorias.

como opsoninas. Los receptores lectina de unión a manana se unen a los carbohidratos de la pared celular de una gran variedad de microorganismos y la marcan para su reconocimiento por la vía de las lectinas de la cascada del complemento: Esta vía se diferencía de la clásica porque no requiere complejos antígeno-anticuerpo. Durante la activación del complemento, también se generan mediadores de inflamación, tales como C5a y C3a, los cuales reclutan macrófagos, NK y neutrófilos. Estos fagocitos ocasionan una reacción inflamatoria local en el sitio de la infección $(31,32)$.

Los patógenos son inmediatamente reconocidos por fagocitos en los tejidos conectivos subepiteliales con tres consecuencias importantes:

1.- Los patógenos son atrapados, englobados y destruídos por macrófagos y neutrófilos. La respuesta se inicia con la identificación de carbohidratos con grandes cantidades de manosa del patógeno, por los receptores para reconocimiento del patrón, localizados en la superficie de los fagocitos. Los receptores de manosa tipo endocíticos median la fagocitosis y liberación del patógeno en los lisosomas donde se procesa el antígeno. Los péptidos resultantes pueden ser presentados por moléculas del complejo mayor de histocompatibilidad en la superficie del macrófago.

2.- La interacción de los patógenos con los fagocitos induce la secreción de citocinas. El estímulo para la síntesis de interleucinas por los macrófagos, probablemente sea la unión del

\section{Revista Biomédica}


Interleucinas e inmunidad innata.

patógeno con los mismos receptores utilizados para su englobamiento. Algunos de los receptores para reconocimiento del patrón, activan vías de transducción de señal que inducen la expresión de una gran variedad de genes de la respuesta inmune, donde se incluyen los genes para citocinas inflamatorias. Los receptores de la familia toll (TLR), se identificaron recientemente y sus vías de transducción de señal conducen a la activación de factores de transcripción de la familia del factor nuclear kappa B (NF-kB). La liberación de citocinas también es inducida por pequeños péptidos liberados en la cascada del complemento.

3.- Los macrófagos funcionan como una célula profesional presentadora de antígenos. En este sentido, los receptores de macrófagos, tienen un papel importante en el secuestro y procesamiento antigénico, así como en la transmisión de señales que inducen la expresión de moléculas coestimuladoras. De esta manera, los macrófagos al liberar ciertos tipos de citocinas determinan la forma de la respuesta inmune (33-36).

Las endotoxinas, tales como LPS, estimulan la producción de interleucinas por parte de los macrófagos y otras células. Las citocinas IL-1 y TNF-a promueven la expresión de moléculas de superficie tales como ICAM y Selectinas sobre células endoteliales, para contribuir a la acumulación de leucocitos en sitios locales de inflamación (figura 1). Igualmente, provocan que fagocitos mononucleares y células endoteliales sinteticen quimiocinas activadoras de leucocitos $(37,38)$. Las quimiocinas C-X-C actúan predominantemente sobre neutrófilos, mientras las quimiocinas $\mathrm{C}-\mathrm{C}$ actúan principalmente en células $\mathrm{T}$, monocitos, eosinófilos y basófilos, pero no neutrófilos $(39,40)$. Además, el TNF-a activa al endotelio vascular e incrementa su permeabilidad, lo cual provoca un incremento en la entrada de $\mathrm{IgG}$, complemento y células a los tejidos e incrementa el fluido de drenaje hacia los nódulos linfoides. Una vez atraídas las células, el TNF-a estimula a neutrófilos, eosinófilos y fagocitos mononucleares para lisar microbios. Los neutrófilos son la principal línea de defensa contra hongos, ya que además de la fagocitosis presumiblemente liberan especies oxigeno reactivas y enzimas lisosomales para ocasionar la eliminación del patógeno (41).

Los microorganismos intracelulares o sus productos inducen la producción de IL-12 por monocitos y neutrófilos. La IL-12 en colaboración con la IL-18, incrementan la función citolítica de células NK y linfocitos T CD8+ activados (CTLs), estimulan la secreción de IFN-g por células $\mathrm{T}$ y $\mathrm{NK}$, y el desarrollo de respuestas tipo Th1 (figura 1) $(42,43)$. La IL-12 se puede clasificar como un regulador de inmunidad innata, debido a que los macrófagos activados por microbios la secretan con la finalidad de desarrollar las funciones efectoras de las células NK. Al mismo tiempo es un importante vínculo entre inmunidad natural e inmunidad adaptativa contra virus y bacterias $(44,45)$.

En respuesta a infecciones virales, la IL-15 es sintetizada tempranamente. Esta citocina es quimioatrayente para células $\mathrm{T}$ y modula sus niveles de moléculas de adhesión. Sobreregula la producción de IFN-gen células NK e incrementa su citotoxicidad (figura 1). Las NK pueden ser activadas directamente por las bacterias intracelulares, sin embargo la IL-15 puede mediar la expansión de células NK dentro de las primeras 24-72 horas de la infección (46,47). Las células infectadas por virus muestran reducidos niveles de moléculas MHC clase-I, lo cual las convierte en blanco para las células NK. El mecanismo de eliminación puede ser a través de la secreción de perforinas y proteasas de serina o por inducción de apoptosis (48). Asimismo, las células NK pueden lisar células infectadas que tengan unidas moléculas IgG en su superficie, en un ejemplo de citotoxicidad celular mediada por anticuerpos. En infecciones parasitarias, el mecanismo de defensa es el mismo. Los helmintos recubiertos por $\operatorname{IgE}$ son reconocidos por los eosinófilos y son destruidos a través de la secreción de gránulos de enzimas sobre ellos (49).

Las citocinas antivirales por excelencia son los

Vol. 12/No. 4/Octubre-Diciembre, 2001 
MA Hernández-Urzúa, A Alvarado-Navarro.

interferones tipo I. Inhiben la replicación viral debido a que inducen en las células la síntesis de enzimas, tales como la 2'-5' oligoadenilato sintetasa, que colectivamente interfieren la replicación del ARN y ADN viral. Esta actividad antimicrobiana puede ser parácrina. Incrementan el potencial lítico de células NK infectadas viralmente en etapas tempranas de una enfermedad, antes del inicio de la respuesta inmune específica (figura 1). Modulan la expresión de moléculas MHC, aumentan la expresión de MHC clase-I y reducen la de MHC clase-II, lo cual aumenta la eficiencia de lisis mediada por linfocitos $\mathrm{T}$ citotóxicos. Además, los IFNs tipo I promueven la liberación de interleucinas pro-inflamatorias y oxido nítrico por células dendríticas y macrófagos (50).

Algunas, citocinas incluyendo IL-1b, IL-6, IL8, TNF-a e IFN-gson importantes activadores de la respuesta de fase aguda (51). En hepatocitos, el TNF-a aumenta la síntesis de proteína amiloide A, mientras la IL-6 estimula la síntesis de fibrinógeno ante los estímulos inflamatorios (Figura 1). Sin embargo, cuando el estímulo para la producción de IL-1, IL-6 y TNF-a es suficientemente fuerte y grandes cantidades de estas citocinas son producidas y entran a la sangre, funcionan como pirógenos endógenos, es decir provocan fiebre. El TNF-a en particular, inicia el debilitamiento metabólico o caquexia. La IL-6 además sirve como factor de crecimiento para las células B activadas, en la fase tardía de su diferenciación $(52,53)$. Asimismo, durante la enfermedad activa, los mastocitos y basófilos son activados para secretar una diversidad de mediadores inflamatorios los cuales incluyen histamina, proteasas neurales, prostaglandinas y leucotrienos, así como una variedad de interleucinas y quimiocinas involucradas en el reclutamiento y activación de leucocitos (54).

Las regulación de esta intrincada red de citocinas está controlada principalmente por la IL10 (figura 1). Su función es interferir la síntesis de las citocinas TNF-a, IL-1, IL-2, IL-6 y GM-CSF por células $\mathrm{T}$ y regular negativamente la síntesis de IL-1, IL-6, IL-8 y TNF-a por macrófagos. Sin embargo, puede potenciar la expresión de IL-15 en macrófagos murinos activados, lo cual de acuerdo a su efecto regulador negativo sobre IL-2 sugiere un soporte paradójico para la respuesta inmune mediada por células. La IL-10, sobreregula la expresión de MHC clase II, soporta el crecimiento y la producción de inmunoglobulinas en células B. La IL-10 inhibe las funciones accesorias de los macrófagos en la activación de las células $\mathrm{T}$, este efecto se debe a la expresión reducida de las moléculas MHC clase-II y de las moléculas coestimuladoras B7-1 y B7-2. El efecto total de estas acciones es inhibir la respuesta inespecífica y la mediada por células $(55,56)$.

Hasta el momento nos hemos enfocado solo en las interacciones entre las células y las citocinas. Sin embargo, no debemos olvidar la participación de los mecanismos de evasión de los patógenos, los cuales pueden modificar la respuesta inmune. Por ejemplo, la inhibición de la producción de IL12 por células accesorias después de una infección por HIV, provoca abatimiento en las respuestas innata y mediada por células Th1 en pacientes con SIDA (57). En infecciones por malaria y tripanosoma se produce una depresión generalizada e inespecífica, debido a la producción de citocinas inmunosupresoras por células $\mathrm{T}$ y macrófagos activados, y por defectos en la respuesta de células $\mathrm{T}$ (58).

\section{CONCLUSIONES.}

Los mecanismos de las respuestas inmune innata y adquirida forman un sistema integrado de defensa del hospedero, en el cual numerosas células y moléculas funcionan colectivamente. La naturaleza de la respuesta inespecífica temprana es un factor de suma importancia, influye en el tipo de respuesta específica que se desarrollará subsecuentemente. De igual manera, la inmunidad adquirida puede intervenir durante la inmunidad natural. En este sentido, los fagocitos

\section{Revista Biomédica}




\section{Interleucinas e inmunidad innata.}

mononucleares son importantes participantes en ambas interacciones. Después de haber ingerido al patógeno, los macrófagos respondedores durante una reacción de inmunidad innata, muestran sobre su superficie antígenos del microorganismo, los cuales pueden ser reconocidos por los linfocitos $\mathrm{T}$ antígeno- específicos. Mientras, las células T y B producen citocinas tales como el IFN-g, con la finalidad de incrementar las funciones microbicidas de los macrófagos,. Por lo tanto, la interrelación entre la inmunidad natural y la específica es bidireccional y está mediada en gran parte por las interleucinas (59-61).

Finalmente, es importante mencionar que constantemente se describen nuevos factores, moléculas y proteínas con diversas propiedades inmunológicas, las cuales son producidas por células que anteriormente no eran consideradas como parte del sistema de defensa del hospedero. Asimismo, los mecanismos de regulación de las interleucinas y su posible aplicación en la medicina clínica permanecen aún por esclarecer, por lo cual el estudio de las citocinas y sus efectos se mantiene como un campo amplio de investigación.

\section{REFERENCIAS.}

1.- Fleisher TA, Bleesing JJ. Immune function. Pediatr Clin North Am 2000; 47:1197-209.

2.- Medzhitov R, Janeway CA Jr. Advances in Immunology: Innate Immunity. N Eng J Med 2000; 343: $338-44$.

3.- Medzhitov R, Janeway C Jr. Innate immune recognition: mechanisms and pathways. Immunol Rev 2000; 173:89-97.

4.- Seder RA, Gazzinelli RT. Cytokines are critical in linking the innate and adaptive immune responses to bacterial, fungal, and parasitic infection. Adv Intern Med 1999; 44:353-88

5.- Rollinghoff M. Immunity, components of the immune system and immune response. Biologicals 1997; 25:1658.

6.- Trinchieri G. Cytokines acting on or secreted by macrophages during intracellular infection (IL-10, IL-12, IFN-gamma). Curr Opin Immunol 1997; 9:17-23.

7.- Oberholzer A, Oberholzer C, Moldawer LL. Cytokine signaling--regulation of the immune response in normal and critically ill states. Crit Care Med 2000; 28 (Suppl):N312.

8.- Gery I, Waksman BH. Potentiation of the Tlymphocyte response to mitogens. II. The cellular source of potentiating mediator(s). J Exp Med 1972; 136:14355.

9.- Dinarello CA. Interleukin-1, interleukin-1 receptors and interleukin-1 receptor antagonist. Int Rev Immunol 1998;16:457-99.

10.- Weissenbach J, Chernajovsky Y, Zeevi M, Shulman $\mathrm{L}$, Soreq H, Nir U, et al. Two interferon mRNAs in human fibroblats: In vitro translation and Escherichia coli cloning studies. Proc Natl Acad Sci USA 1980; 77:7152-6.

11.- Taga T, Kishimoto T. Gp130 and the interleukin-6 family of cytokines. Annu Rev Immunol 1997;15:797-819.

12.- Yoshimura T, Matsushima K, Tanaka S, Robinson EA, Appella E, Oppenheim JJ, et al. Purification of a human monocyte-derived neutrophil chemotactic factor that has peptide sequence similarity to other host defense cytokines. Proc Natl Acad Sci USA 1987; 84: 9233-7.

13.- Ward SG, Westwick J. Chemokines: understanding their role in T-lymphocyte biology. Biochem J 1998; 333 (Pt 3):457-70.

14.- Moser B, Loetscher M, Piali L, Loetscher P. Lymphocyte responses to chemokines. Int Rev Immunol 1998; 16:323-44.

15.- Kobayashi M, Fitz L, Ryan M, Hewick RM, Clark $\mathrm{SC}$, Chan S, et al. Identification and purification of natural killer cell stimulatory factor (NKSF), a cytokine with multiple biologic effects on human lymphocytes. J Exp Med 1989; 170: 827- 45.

16.- Gately MK, Renzetti LM, Magram J, Stern AS, Adorini L, Gubler U, et al. The interleukin-12/interleukin12-receptor system: role in normal and pathologic immune responses. Annu Rev Immunol 1998;16:495-521.

17.- Trinchieri G. Immunobiology of interleukin-12. Immunol Res 1998; 17:269-78.

Vol. 12/No. 4/Octubre-Diciembre, 2001 


\section{MA Hernández-Urzúa, A Alvarado-Navarro.}

18.- Isaacs A, Lindenmann J. Virus interference. I. The interferon. Proc Natl Acad Sci USA 1957; 147:258.

19.- Sinigaglia F, D'Ambrosio D, Rogge L Type I interferons and the Th1/Th2 paradigm. Dev Comp Immunol 1999; 23:657-63.

20.- Carswell EA, Old LJ, Kaseel RL, Green S, Fiore N, Williamson B. An endotoxin-induced serum factor that causes necroses of tumors. Proc Natl Acad Sci USA 1975; 72: 3666-74.

21.- Brouckaert P, Libert C, Everaerdt B, Takahashi N, Cauwels A, Fiers W. Tumor necrosis factor, its receptors and the connection with interleukin 1 and interleukin 6 . Immunobiology 1993; 187:317-29.

22.- Burton JD, Bamford RN, Peters C, Grant AJ, Kurys G, Goldman CK, et al. A lymphokine, provisionally designed interleukin $\mathrm{T}$ and produced by a human adult $\mathrm{T}$ cell leukemia line, stimulates T-cell proliferation and the induction of lymphokine-activated killer cells. Proc Natl Acad Sci USA 1994; 91:4935-9.

23.- Waldmann T, Tagaya Y, Bamford R. Interleukin-2, interleukin-15, and their receptors. Int Rev Immunol 1998; 16:205-26.

24.- Fiorentino DF, Bond MW, Mosmann TR. Two types of mouse helper T cell. IV. Th2 clones secrete a factor that inhibits cytokine production by Th1 clones. J Exp Med 1989; 170:2081-95.

25.- Stordeur P, Goldman M. Interleukin-10 as a regulatory cytokine induced by cellular stress: molecular aspects. Int Rev Immunol 1998; 16:501-22.

26.- Nakamura K, Okamura H, Wada M, Nagata K, Tamura T. Endotoxin-induced serum factor that stimulates gamma interferon production. Infect Immun 1989; 57:5909.

27.- Lebel-Binay S, Berger A, Zinzindohoue F, Cugnenc P, Thiounn N, Fridman WH, et al. Interleukin-18: biological properties and clinical implications. Eur Cytokine Netw 2000 Mar;11:15-26.

28.- Dinarello CA. IL-18: A TH1-inducing, proinflammatory cytokine and new member of the IL-1 family. J Allergy Clin Immunol 1999; 103:11-24.

29.- Risso A. Leukocyte antimicrobial peptides: multifunctional effector molecules of innate immunity. $\mathbf{J}$

\section{Revista Biomédica}

Leukoc Biol 2000; 68:785-92.

30.- Ochsenbein AF, Zinkernagel RM. Natural antibodies and complement link innate and acquired immunity. Immunol Today 2000; 21:624-30.

31.- Nonaka M. Evolution of the complement system. Curr Opin Immunol 2001; 13:69-73.

32.- Zhang Y, Suankratay C, Zhang XH, Lint TF, Gewurz H. Lysis via the lectin pathway of complement activation: minireview and lectin pathway enhancement of endotoxininitiated hemolysis. Immunopharmacology 1999; 42:8190.

33.- Ulevitch RJ, Tobias PS. Receptor-dependent mechanism of cell stimulation by bacterial endotoxin. Annu Rev Immunol 1995; 13:437-57.

34.- Linehan SA, Martinez-Pomares L, Gordon S. Macrophage lectins in host defence. Microbes Infect 2000; 2:279-88.

35.- Kopp EB, Medzhitov R. The Toll-receptor family and control of innate immunity. Curr Opin Immunol 1999; 11:13-8.

36.- Stein-Streilein J, Sonoda KH, Faunce D, ZhangHoover J. Regulation of adaptive immune responses by innate cells expressing NK markers and antigentransporting macrophages. J Leukoc Biol 2000; 67:48894.

37.- Murphy JE, Robert C, Kupper TS. Interleukin-1 and cutaneous inflammation: a crucial link between innate and acquired immunity. J Invest Dermatol 2000; 114:602-8.

38.- Beutler BA. The role of tumor necrosis factor in health and disease. J Rheumatol 1999;26 (Suppl 57):1621.

39.- Mantovani A. The chemokine system: redundancy for robust outputs. Immunol Today 1999; 20:254-7.

40.- Lukacs NW, Kunkel SL. Chemokines and their role in disease. Int J Clin Lab Res 1998; 28:91-5.

41.- Bogdan C, Rollinghoff M, Diefenbach A. Reactive oxygen and reactive nitrogen intermediates in innate and specific immunity. Curr Opin Immunol 2000; 12:64-76.

42.- Boyaka PN, Lillard JW Jr, McGhee J. Interleukin 12 and innate molecules for enhanced mucosal immunity. 


\section{Interleucinas e inmunidad innata.}

Immunol Res 1999; 20:207-17.

43.- Akira S. The role of IL-18 in innate immunity. Curr Opin Immunol 2000; 12:59-63.

44.- Trinchieri G. Proinflammatory and immunoregulatory functions of interleukin-12. Int Rev Immunol 1998; 16: 36596.

45.- Spellberg B, Edwards JE. Type 1/Type 2 immunity in infectious diseases. Clin Infect Dis 2001; 32:76-102.

46.- Yoshikai Y, Nishimura H. The role of interleukin 15 in mounting an immune response against microbial infections. Microbes Infect 2000; 2:381-9.

47.- Carson W, Caligiuri MA. Interleukin-15 as a potential regulator of the innate immune response. Braz J Med Biol Res 1998; 31:1-9.

48.- Vales-Gomez M, Reyburn H, Strominger J. Interaction between the human NK receptors and their ligands. Crit Rev Immunol 2000; 20:223-44.

49.- Meeusen EN, Balic A. Do eosinophils have a role in the killing of helminth parasites? Parasitol Today 2000; 16: $95-101$.

50.- Bogdan C. The function of type I interferons in antimicrobial immunity. Curr Opin Immunol 2000; 12:41924.

51.- Suffredini AF, Fantuzzi G, Badolato R, Oppenheim JJ, O'Grady NP. New insights into the biology of the acute phase response. J Clin Immunol 1999; 19:203-14.

52.- Gadient RA, Otten UH. Interleukin-6 (IL-6)-a molecule with both beneficial and destructive potentials. Prog Neurobiol 1997; 52:379-90.

53.- DiPiro JT. Cytokine networks with infection: mycobacterial infections, leishmaniasis, human immunodeficiency virus infection, and sepsis. Pharmacotherapy 1997; 17:205-23.

54.- Holgate ST. The role of mast cells and basophils in inflammation. Clin Exp Allergy 2000;30 (Suppl 1):28-32.

55.- Smith EM, Cadet P, Stefano GB, Opp MR, Hughes TK Jr. IL-10 as a mediator in the HPA axis and brain. J Neuroimmunol 1999; 100:140-8.

56.- Opal SM, De Palo VA. Anti-inflammatory cytokines.
Chest 2000; 117:1162-72.

57.- Ma X, Montaner LJ. Proinflammatory response and IL-12 expression in HIV-1 infection. J Leukoc Biol 2000; 68:383-90.

58.- McNicholl JM, Downer MV, Udhayakumar V, Alper CA, Swerdlow DL. Host-pathogen interactions in emerging and re-emerging infectious diseases: a genomic perspective of tuberculosis, malaria, human immunodeficiency virus infection, hepatitis B, and cholera. Annu Rev Public Health $2000 ; 21: 15-46$.

59.- Gough PJ; Gordon S. The role of scavenger receptors in the innate immune system. Microbes Infect 2000; 2: 30511.

60.- Medzhitov R, Janeway CA Jr. Innate immunity: impact on the adaptive immune response. Curr Opin Immunol 1997; 9:4-9.

61.- Banyer JL, Hamilton NH, Ramshaw IA, Ramsay AJ. Cytokines in innate and adaptive immunity. Rev Immunogenet 2000; 2:359-73. 